\title{
LA MORALIDAD. HEGEL VERSUS KANT (II)'
}

\author{
Jacinto RIVERA DE ROSALES. \\ UNED
}

RESUMEN: Se analizan los argumentos que Hegel elabora contra la moralidad kantiana en el tercer momento de la Moralität o segunda etapa del Espíritu objetivo, a saber, "El bien y la conciencia moral» 0 "El bien y el mal morales». Estas criticas son las de que el sujeto moral kantiano es vacio y formal, y en consecuencia incapaz de determinar los deberes concretos, por lo cual da entrada a la arbitrariedad y al mal, y además de que se mantiene en la dualidad entre el ser y el deber ser, entre la naturaleza y el bien. Frente a ello se expone la libertad kantiana como realidad en si, que es contenido último de su propia acción y capacidad de establecimiento de los vinculos morales entre los hombres, más el aspecto positivo y teleológico de nuestra naturaleza según la filosofia critica. Hegel propiamente no dialoga con Kant, sino con una figura construida en su proceso dialéctico.

\section{Introducción. El bien y la conciencia moral}

Kant constituye un referente continuo en la obra de Hegel. Para él Kant, junto con Fichte, al que cita menos pero quizás sigue más, es el punto culminante de la filosofía moderna. Enfrentarse con él (o ellos) significa, por tanto, mostrar las insuficiencias de los planteamientos filosóficos de la modernidad en sus mismos fundamentos y la subsiguiente novedad de su propia propuesta, que sería capaz de aunar lo comunitario y lo individual, lo griego y lo moderno. De éste valora el desarrollo de la subjetividad libre como individuo autónomo, y critica fundamentalmente que, según él, se haya quedado en el limite y la escisión propia del pensamiento abstracto, aquél que no es capaz de superar todo tipo de

${ }^{1}$ Con el «(II)» quiero indicar que este trabajo continúa las reflexiones de otro anterior, titulado asimismo "La moralidad. Hegel versus Kant (I)", publicado en La controversia de Hegel con Kant, eds. Mariano Álvarez Gómez y Mª del Carmen Paredes Martín, Ediciones Universidad de Salamanca, 2004, págs. 161-178. Pero, aunque ambos se complementan, pueden leerse separadamente. 
dualidad y alzarse al verdadero Absoluto. Éste, como horizonte último de todo el filosofar verdadero, volvería a unir la subjetividad con la objetividad, la interioridad de la una con la legalidad y realidad efectiva de la otra, o sea, la certeza del sujeto con la verdad de la obra, hacia la cual hay un impulso extraordinariamente potente en el pensamiento de Hegel.

Pero el presente trabajo no quiere hacer un balance global de esa confrontación entre dos modos bien distintos de filosofar, entre dos paradigmas de pensamiento, sino centrarse en un momento parcial de ellos, uno de los más conocidos: el de la moralidad, segundo momento del Espíritu objetivo, situado entre el derecho abstracto y la eticidad, a fin de hacer, tal vez, una propuesta diferente de interpretación: el encuentro en realidad no tuvo lugar. Quiero decir que Hegel no dialoga propiamente con Kant, sino con una figura construida según las exigencias de su método dialéctico, por el que se delinea un punto de vista moral totalmente diferenciado del ético, o sea, una conciencia moral meramente formal frente a la verdadera conciencia ética ${ }^{2}$, lo que da como resultado una figura que hace de fantasma interpuesto. Él sólo destruye al final su propio producto. Son conocidas las deformaciones que los filósofos sistemáticos llevan a cabo de los otros pensadores, y Hegel se encuentra entre ellos. Tal vez ése haya sido el precio de su excepcional potencia creadora en el ámbito del concepto. Pero poner en claro sus limitaciones interpretativas, triunfantes aún en la actualidad, puede ser todavía hoy un buen modo de presentar y renovar a Kant, de convertirlo en algo vivo para nuestro tiempo.

En este artículo me propongo continuar otro anterior en donde lo dejé. Allí expuse los dos primeros momentos de la moralidad (Moralität): el propósito y la intención, más las críticas formuladas por Hegel a la ética de la mera intención (de la Gesinnung) y a un deber que excluiría de sí la felicidad. Ambas van directamente al corazón de la moral kantiana según la visión que ya se ha hecho tópica de la misma. Pero en ese mismo artículo me esforcé por aclarar cómo hemos de entender dicha intención moral para que no nos conduzca a absurdos éticos,

2 «En el punto de vista moral, tal como es diferenciado del ético en este tratado, sólo entra la conciencia moral formal; la conciencia moral verdadera ha sido mencionada [en este $\$ 137$, perteneciente aún a la moralidad] únicamente para señalar su diferencia y eliminar el posible malentendido de creer que aquí, donde se examina la conciencia moral formal, se estuviera hablando de la verdadera, la cual está contenida en la disposición de ánimo ético, que aparecerá sólo en lo que sigue» (FD [= Fundamentos de la Filosofia del derecho] \$137 A; W. VII, 256). 
y que la felicidad, lejos de estar excluida de la moralidad kantiana, forma parte de tareas morales y del bien supremo exigido por la razón moral junto con la virtud, si bien no es el criterio último de moralidad, como tampoco lo es para Hegel. Es hora de discutir la tercera figura o etapa de la moralidad, la titulada "El bien y la conciencia moral», con el mismo propósito de revisión. Nuestros textos básicos siguen siendo la Enciclopedia (Enz) y Los fundamentos de la filosofia del derecho (FD), pero también se tendrán en cuenta la Fenomenología del Espíritu (FE) y las Lecciones sobre la historia de la filosofia ( $H F)$, cuando exponen el pensamiento de $\mathrm{Kant}^{3}$.

A ese tercer momento de la moralidad lo denomina la FD «el bien y la conciencia moral» y la Enz «el bien y el mal» (morales), lo cual nos indica ya que la conciencia moral será la puerta de entrada al mal moral, y con ello de una negatividad que habrá de ser resuelta en la eticidad, si es que eso fuera alcanzable. El tránsito a este tercer momento viene posibilitado por el problema que no pudo resolver el estadio anterior -el de la intención y el bienestar-, a saber, el derecho de indigencia (Notrecht). Cuando alguien está en peligro de muerte, por ejemplo, por falta de alimento o por frío, ¿tiene derecho a robar? Aquí entran en contradicción la propiedad de uno, sancionada por derecho abstracto, y la particularidad del otro sujeto con su derecho al bienestar, a la afirmación de su particularidad y, por tanto, de su vida, sin la cual el mismo derecho abstracto deja de tener realidad. Pero también a la inversa; la particularidad de uno, dado que ésta es un derecho u objetivación de la libertad, no puede ir en contra de otra objetivación de la libertad sin arruinar su propia base. No cabe, en consecuencia, justificar una acción contraria a derecho porque se tenga la intención del bienestar, ni aunque fuera el de los otros, como pretendían los buenos bandoleros que robaban a los ricos para repartirlo entre los pobres ${ }^{4}$. La vida natural del individuo es de suyo algo contingente, y sólo alcanźa valor dentro del mundo de la libertad y como objetivación de la misma. Pero en ese ámbito se ha de reconocer que la vida es el conjunto y subsuelo de todos los intereses, propósitos e intenciones de la voluntad natural, sin la cual resulta imposible cualquier otro, ni bienestar alguno. Por consiguiente, ella tiene derecho a la vida si es que tiene derecho a algo. Por otra parte podríamos recordar, aunque Hegel no lo haga aquí, que si las eta-

${ }^{3}$ De sus primeros escritos habriamos de destacar Sobre las maneras de tratar cientificamente el derecho natural (1802-3) con su crítica a la vaciedad del sujeto kantiano.

${ }^{4}$ Hegel cita al drama Los bandidos de Schiller y a san Crispín (FD $\$ 126 \mathrm{z}$ ). 
pas posteriores expresan derechos superiores, el derecho a la vida es superior al de la propiedad. Luego en peligro de vida se tiene un derecho a la propiedad del otro, si bien limitado a ese momento ${ }^{5}$, por ejemplo, a robar un pan, se atrevía a decir Hegel, pero sólo en sus lecciones orales: «Eso es, el hombre tiene derecho a esa acción ilegal. Pues la vida es la totalidad de la particularidad [...] Si el hombre en peligro de muerte no debiera hacer eso, entonces se le determinaría como carente de derechos (rechtlos) ${ }^{6}$, con la imposibilidad de ejercer ninguno de ellos a causa de la muerte.

Pues bien, este antagonismo entre propietarios y desposeídos es irresoluble a este nivel, pues en él sólo nos encontramos con las voluntades particulares en búsqueda de su interés particular. En la siguiente etapa, la del bien y de la conciencia moral, el sujeto se eleva a la universalidad (pero aún abstracta), e intenta integrar esos dos momentos: la existencia de la voluntad particular y la universalidad de la libertad y sus derechos. Tampoco lo logrará, y el antagonismo vuelve a resurgir en el segundo momento de la eticidad, el de la sociedad civil, con su lucha de intereses y de clases. Y allí vemos que Hegel tampoco encuentra medios para hacer frente a la progresiva pauperización de las masas en la reciente sociedad industrial'

El tercer momento de la moralidad, el del bien moral, es el punto álgido de la crítica de Hegel a la moral kantiana. En el bien moral (das Gute) es donde encuentran su unidad el derecho abstracto (das Recht) y el bienestar de la voluntad particular (das Wohl), pero no por mera yuxtaposición (ese nunca es el sentido de la Aufhebung hegeliana), sino remitiéndose entre sí y subordinados al primero. El bien en cuanto tal «es el contenido de la voluntad universal que existe en y para sí [...] el fin final absoluto del mundo y el deber para el sujeto ${ }^{8}$, y por consiguiente marca el camino tanto a la moralidad como a la eticidad. En esta nece-

${ }^{5} F D \$ 127$.

${ }^{6}$ Apuntes de clase de H. G. Hotho 1822/23 (Hegel, Rechtsphilosophie, ed. Ilting, Frommann, Stuttgart, 1974, t. III, pp. 400-401).

${ }_{7}$ «El buen Hegel no sabe muy bien qué hacer (cf $[F D] \$ 244$ ), salvo señalar para ella [para la plebe de desheredados] el «auxilio social» $(\$ 241)$, el camino de las colonias $(\$ 248)$ y en fin, a falta de otra solución, la usolución escocesa»: abandonar a los miserables a su suerte y a la mendicidad pública $(\$ 245, A)$, aunque Hegel reconozca que la limosna es deshonrosa $(\$ 242, A)$ ) (Félix Duque, Historia de la filosofia moderna. La era de la critica, Akal, Madrid, 1998, p. 828). Esta última observación es un poco maliciosa, pues a contiuación, en ese mismo $\$ 245$, Hegel critica dicha situación en Escocia, ya que ocasiona la pérdida del pudor y de la dignidad, bases subjerivas de la sociedad.

${ }^{8}$ Enz. $\$ 507$. 
saria relación al bien, por el lado subjetivo tenemos la buena intención del sujeto en su conciencia moral y por el lado objetivo el derecho y el bienestar, de tal manera que no debería darse el bienestar sin derecho, sin la universalidad en sí, ni el derecho sin el bienestar de las voluntades particulares, pues ambos, como universalidad y particularidad, son objetivaciones necesarias de la libertad, momentos del Espíritu objetivo que han de mediatizarse mutuamente'. Aparece aquí con toda su fuerza la Idea, o sea, la unidad del concepto y de su realización, en el ámbito de la acción libre, lo cual llegará a su plenitud en la eticidad. Ahora, sin embargo, en la Moralität estamos sólo en su primer momento, en la primera aparición de la idea de bien, sin articulación y sin mediaciones específicas con sus partes. Al estar aún comprendido el bien de una manera tan general y abstracta, no se encuentran aquí especificadas sus concreciones, es decir, los deberes concretos, y por lo que respecta al lado subjetivo mantiene con la voluntad particular (la que anteriormente buscaba su propiedad y su bienestar) una relación conflictiva. Sólo a través de la voluntad particular, la universal puede hacerse efectiva en el mundo, pero a aquélla le queda un duro trabajo sobre sí misma (formación y virtud) para acoger en sí a ésta, aunque en verdad sea su propia esencia libre y racional. Por eso mantiene con ella no una identificación sino una relación (Verhältnis), y en concreto la del deber u obligación ${ }^{10}$, lo cual abre las puertas al albedrío y a la contingencia, y en consecuencia al mal moral. Ésas serán las insuficiencias de la moral kantiana según Hegel y los puntos de fuga que marcarán el tránsito a la eticidad.

En el ámbito del propósito, la cuestión (por ejemplo policial o detectivesca) era saber si ha sido mi acción, querida y sabida, la que ha causado algo, o si esto fue efecto más bien de otras causas ajenas a mi voluntad. En el ámbito de la intención se trataba de ver si yo, haciendo esa acción, quería causar esto o lo otro y, en el límite, si mi intención era causar el bien o el mal. Para dilucidarlo y determinar con ello mi responsabilidad sobre lo ocurrido, se recurre a la justificación, es decir, a la transformación de la intención subjetiva en bien universal pronunciando un juicio universal sobre mi acto concreto, declarándolo bueno. Si antes, tanto en el propósito como en la intención, veíamos que el derecho de la voluntad subjetiva era el de serle imputado sólo lo que ella hacía de manera deliberada, aquí su derecho es el de no reconocer nada como racional y bueno si

\footnotetext{
${ }^{9} F D \$ \$ 130-131$.

${ }^{10} F D \$ \$ 108$ y 131.
} 
él no lo ve así; por eso, aquellos que son incapaces de discernir, como ocurre con los niños y los idiotas, carecen de responsabilidad moral. Ese es el supremo derecho del sujeto, no estar obligado a considerar como bueno lo que contradice sus convicciones racionales, o sea, su derecho "sagrado" a la conciencia moral ${ }^{11}$. Es el punto de vista kantiano, el de la autonomía racional del sujeto; el gran logro de la filosofía moral de Kant es "poner de relieve la pura e incondicionada autodeterminación de la voluntad como la raíz del deber» ${ }^{12}$. Es a la vez el punto de vista del mundo moderno que, como sabemos, para Hegel se inicia con el cristianismo. La conciencia moral (das Gewissen) es la subjetividad absolutamente cierta de su libertad y la que decide enteramente su acción desde su propia responsabilidad. «La conciencia moral es esa hondísima soledad interna consigo mismo, donde todo lo externo y toda limitación han desaparecido" ${ }^{13}$.

Ahora bien, este derecho subjetivo no elimina el derecho de lo objetivamente racional, añade $\mathrm{Hegel}^{14}$. El sujeto puede estar equivocado en su convicción, y eso es algo contingente y ajeno al bien moral, lo cual debe ser superado por medio de una formación o educación que eleve a esa conciencia particular a lo universal, a lo objetivamente racional ${ }^{15}$, expresado en la eticidad y en las leyes públicas y publicadas del Estado. Esa soledad de la conciencia será, por tanto, también su abismo, su posibilidad de mal, la razón de sus antinomias según Hegel, las cuales representarán otras tantas críticas a la moral kantiana, las más poderosas, impactantes e influyentes. Veámoslas, agrupándolas en tres grandes bloques, aunque están relacionadas entre sí.

\section{Del sujeto vacío al sujeto como realidad originaria}

En la moralidad hegeliana, el sujeto se ha retirado enteramente a sí, a su interior, y con el fin de afirmar su libertad, en la forma de una total autonomía, ha roto todo lazo de unión (Band) con los otros y con la objetividad, tanto con la objetividad natural como con la de la libertad objetivada en la eticidad del pueblo (familia, sociedad civil y Estado); se ha retirado, como hemos visto, a su más

\footnotetext{
${ }^{11} F D \$ 132$ nota y 137 nota.

${ }^{12} F D \subseteq 135 \mathrm{~A}$.

${ }^{13} F D @ 136 \mathrm{Z}$.

${ }^{14} F D \$ 132$ nota.

${ }^{15} F D \$ 20-21187$.
} 
íntima soledad. Pero justamente por eso mismo el sujeto se ha quedado en una libertad meramente formal y abstraída del resto, vaciada de cualquier contenido y abocada a la más absoluta arbitrariedad en sus decisiones: «esa libertad es primeramente vacía (leer), lo negativo de todo lo demás; ningún lazo de unión, ninguna cosa me obliga. Ella es en esa medida indeterminada [...] Aquí estamos por tanto de nuevo en la carencia de contenido (Inhaltlosigkeit) " ${ }^{16}$. Por eso, el sujeto en la moralidad kantiana y fichteana ve la realidad desde el punto de vista de la escisión, de la diferencia y del dualismo, que es el punto de vista de la finitud; es una conciencia enfrentada a toda objetividad y exterioridad.

El primer paso del Espíritu objetivo fue identificar su libertad únicamente con la cosa exterior y considerarla de su propiedad. Ahora, en el otro extremo de un movimiento dialéctico y pendular, al final del segundo momento, después de un proceso continuo de retorno hacia sí, nos encontramos con una interioridad subjetiva carente de todo ser y que se piensa igualmente como la existencia más acabada y completa de la libertad, del concepto. Es fácil, sin embargo, comprender la unilateralidad de esta figura así descrita. La eticidad hegeliana se propondrá, por tanto, la unión sintética de ambos extremos, pero de nuevo no como mera yuxtaposición, sino porque se descubre la realidad de fondo, la fuerza objetivamente configuradora del concepto en sí, que se servía de los momentos anteriores y los atravesaba para llevar a cabo su obra, objetivada esta vez en la vida ética de la familia, de la sociedad civil y del Estado. En consecuencia, el sujeto moral es una pieza del sistema dialécticamente construida que, y esa es mi tesis, no coincide con el sujeto moral kantiano, ni con el fichteano ${ }^{17}$, de manera que se puede decir que aquí Hegel no dialoga propiamente con ellos, sino consigo mismo. Su crítica no alcanza a Kant ni a Fichte, sino a su propia construcción. Ellos hablan de otro sujeto, o de otro nivel de la subjetividad, que denominan transcendental.

En efecto, la experiencia moral es interpretada por Kant (y por Fichte) no como aquella que conduce al sujeto al vacío de sí, o que parte de esa carencia, es decir, no como la experiencia de un sujeto que se encontrara siendo la nada sartriana, le néant del pour-soi enfrentado a todo ser o en-soi, sino que es la apertura de la conciencia que va más allá de los fenómenos - modo de ser objetivo y con-

${ }^{16} H F, \mathrm{~W} . \mathrm{XX}, 367-368$.

17 Hablo de la filosofía que Fichte elabora en Jena. La posterior habría que comprenderla desde otros parámetros. 
dicionado- hacia el ser originario ${ }^{18}$. Ella es la puerta de entrada a la libertad, a la acción originaria que sabe de sí, donde saber y ser, en su máxima acepción o primer analogado, se unifican en la forma de deber-ser. Aquí encontramos, dice Kant, "la magnífica apertura, que nos acontece por la razón pura práctica gracias a la ley moral, a saber, la apertura a un mundo inteligible mediante la realización del concepto, en otro caso transcendente, de la libertad ${ }^{19}{ }^{19}$, el camino hacia el ser incondicionado ${ }^{20} \mathrm{y}$ fontanal. $Y$ dado que todo saber requiere distinción, ella es la que nos conduce a la vez a la conciencia ontológicamente correcta de los diferentes modos en los que se dice el ser: el modo de ser de la cosa con sus categorías, como útil o medio, y el de la persona en cuanto ser originario; o sea, frente a la dignidad ontológica de esa libertad moral se comprende a la vez la posición subordinada de lo meramente cósico y heterónomo. El ser originario es entonces comprendido como acción autónoma (agilidad, decía Fichte) que sabe de sí, acción protagonizada o libertad, que se pone por tanto como fin último para sí mismo (alfa y omega) y que inicia su andadura en ese mero intento de ser por sí, si bien su instalación en el mundo, o sea, la configuración de la realidad empírica según sus exigencias, sea una tarea que está siempre en camino. La conciencia moral no remite a un vacío de ser o de contenido, sino que es vista como la ratio cognoscendi o vía para conocer y poder afirmar con fundamento la libertad en cuanto acción real e ideal, pues sólo ella puede ser pensada y puesta como ratio essendi o fundamento de dicha conciencia ${ }^{21}$. ¿Cómo podría ser ella absoluta certeza de sí, según se expresa Hegel, si careciera de todo contenido, es decir, en el vacío ontológico, en lo puramente negativo, en la total carencia de verdad? La acción meramente ideal (conciencia) encuentra su apoyo en la acción real/ideal (libertad) y la refleja en la conciencia moral, pues no puede haber reflejo sin luz originaria.

${ }^{18}$ En otro contexto, hablando del segundo momento de la voluntad, Hegel acusa a Fichte de lo contrario, de pensar al Yo sólo como lo positivo, de manera que la limitación le vendría de fuera $(F D \$ 6 \mathrm{~A})$. Pues tampoco eso es enteramente así, pues el Yo es fundamento ideal de su limitación, y sólo así ella es algo para él, mientras que el No-Yo constituye únicamente su fundamento real (véase Fichte, Fundamento de toda la Doctrina de la ciencia, FW I, 174-176 = GA I/2, 325-326, trad. Aguilar, Buenos Aires, 1975, pp. 68-69). Sobre este tema me he extendido más en el artículo "Die Begrenzung. Vom Anstoß zur Aufforderung" (Fichte-Studien, no 16, 1999, pp. 167-190).

${ }^{19} \mathrm{Kp} V$ [Crítica de la razón práctica] A 168, Ak.-Ausg. V, 94.

${ }^{20}$ Gracias a la libertad podemos «determinar aquel concepto racional transcendente [para la razón teórica] de lo incondicionado, y de esta manera, conforme al deseo de la metafísica, ir más allá del límite de toda experiencia posible con nuestro conocimiento a priori, pero sólo con un propósito práctico" (KrV [Crítica de la razón pura] B XXI).

${ }^{21}$ Kant, KpVA 5 nota, Ak.-Ausg. V, 4. 
En otras palabras, la autonomía y espontaneidad ideal sólo puede surgir de una autonomía y espontaneidad real e ideal que se ha escindido con motivo de la limitación o finitud real y de ese modo, en la contraposición que la constituye, ha tomado conciencia reflexiva de su propio ser como autonomía y espontaneidad desdoblada en acción y conciencia de sí, o sea, como libertad.

Hegel, y con él gran parte de la recepción kantiana, ha confundido aquí el ser y los contenidos empíricos y sociales, de los que ciertamente se abstrae en la formulación de la ley moral en cuanto tal (su "parte post»), con el ser y el contenido originarios, que dan lugar a esa misma ley y de los que por tanto no cabe abstraer (su "parte ante»). Es una distinción que, sin embargo, cabe observar en el proceso de desvelamiento de la libertad que se lleva a cabo en los primeros parágrafos de la $K p V$. Como es bien sabido, Kant procede ahí a eliminar de la ley moral todo apoyo en contenidos u objetos queridos, tanto empíricos como transcendentes (ultramundanos o divinos), pues todos ellos sin excepción aparecen debido a nuestra finitud y dependencia, y no es ella la que nos hace ingresar en el ámbito de lo moral. Desde ese punto de vista, la ley moral es puramente formal, a saber, la exigencia de legalidad, que constituye el carácter mismo de la razón, es decir, el requerimiento de universalidad e identidad (o coherencia) en el transcurso de la propia multiplicidad (de acciones, de principios, de sujetos). Pero, dicho esto, no debemos dejar de pensar, o sea, no podemos detener ahí el pensamiento, aunque el texto kantiano haya sido interpretado repetidas veces en ese sentido, sino que tenemos que seguir indagando de qué ser procede esa exigencia racional. Ninguna exigencia surge de la nada ontológica, y menos aún ésta, que es originaria, la petición de lo incondicionado para el actuar. En relación con lo empírico la calificamos de formal, pues todo objeto o exterioridad la destruiría si es puesto como su fundamento real, pero es constitutiva de nuestra racionalidad y, por consiguiente, expresa las más hondas aspiraciones de nuestro ser. Sabemos que la razón es para Kant la manifestación de los últimos intereses del sujeto; la razón teórica es la conciencia de sus metas en el conocer, en la idealidad, y la práctica, las exigencias que su acción real se pone a sí misma. Si no olvidamos esto, entonces lo que desde el punto de vista empírico aparecía como mera forma, desde el transcendental se muestra como la forma requerida de y por la acción originaria. Y ese es su ser y su contenido de fondo, siempre y categóricamente, su fin en sí y último, aquello que se expone como autónomo y que no tolera ser tratado como puro medio en el ámbito de la finitud. 
Por eso mismo la conciencia moral no es rompimiento de todo vínculo, como lo interpreta Hegel, sino todo lo contrario, el establecimiento del verdadero vínculo con la realidad en sus diferentes modos de ser, tanto con lo divino (fe racional), como con los otros o la comunidad ("las relaciones morales del hombre con el hombre" ${ }^{22}$ ), y con el mundo como instrumento de la libertad y, en cierta medida, como casa en cuanto naturaleza viva y manifestación de una subjetividad prerreflexiva (al menos "como si»), lo que llegaría hasta nuestro cuerpo ${ }^{23}$. Ese vínculo moral, el más fuerte y decisivo, el que determina la posibilidad y las acciones, el que une en sí a todos los modos de ser de una forma ontológicamente acertada, es lo que Kant denomina "reino de fines", que se expande por el derecho, la moral y la religión, y en general por todas las manifestaciones humanas. La razón de esa divergencia radical en las visiones es que Hegel sitúa en definitiva a su sujeto moral y a su conciencia en el ámbito del individuo y, en último extremo (aunque esto pueda y deba parecer contradictorio), de lo sensible (o quizás sea mejor decir del Espíritu subjetivo), mientras que Kant (y Fichte) lo colocan en lo transcendental y lo no sensible. Que el Yo de Kant y el de Fichte sea sólo el individuo (aislado) es el tour de force que inició ya Schelling y retomó Hegel; se trata de un tópico de lucha entre modos distintos de pensar, que se encontraban en competencia, dirigido a quedarse con la escena filosófica. En efecto, Hegel afirma que "el sistema objetivo de estos principios y deberes, y la unión del saber subjetivo con el mismo, existe por vez primera en el punto de vista de la eticidad. Aquí, en el punto de vista formal de la moralidad, la conciencia moral existe sin ese contenido objetivo, y de ese modo es para si la certeza infinita y formal de sí mismo que, justamente por eso, es la certeza de este sujeto ${ }^{24}$. Si tenemos en cuenta además que se trata de un individuo aislado en su interioridad vacía, la consecuencia es clara: «Lo que es derecho y deber, en cuanto lo racional en sí y por sí de las determinaciones de la voluntad, no es esencialmente ni la propiedad particular de un individuo ni tampoco es en la forma de sensación o de cualquier otro saber individual, es decir, sensible» ${ }^{25}$. Ese sujeto constituye para Hegel la disolución anárquica y escéptica de todo lo valioso,

22 Kant, Metafisica de las costumbres, Ak.-Ausg. VI, 491.

${ }^{23}$ Sobre esto último, que puede ser más polémico, he publicado un libro titulado La Crítica del Juicio teleológico y la corporalidad del sujeto. (UNED, Madrid, 1988).

${ }^{24} F D \$ 137$, el subrayado es del propio Hegel.

${ }^{25} \mathrm{FD} \$ 137 \mathrm{~A}$. Es evidente la oposición que aquí ejerce Hegel contra los liberales Friesianos, pero eso no debe impedirnos el establecimiento de claras diferencias respecto a las posiciones kantianas y fichteanas. 
de «lo más sagrado, que es lo que por toda la eternidad une más y más a los espíritus, el vínculo realmente substancial" que es la eticidad ${ }^{26}$.

Desde el punto de vista kantiano, esa manera de plantear el sujeto moral se sitúa aún en un modo de pensar precrítico, o si se quiere aristotélico, como opinan los comentaristas de Hegel. El vuelco copernicano al que apunta el método transcendental consiste justamente en descubrir a la subjetividad, que tradicionalmente había sido percibida sólo como principio del caos y de lo arbitrario, fuente de escepticismo, de inmoralidad y de aislamiento, como siendo también en su ser originario el verdadero principio de orden y ligazón, tanto de ordenación objetiva (experiencia fenoménica, técnica y científica), como de ordenación buena y justa de las acciones libres (moral y derecho) y de comunicación incluso del sentimiento (estética). Así es al menos su nivel transcendental, en su posible contraposición con lo empírico; aquél es vínculo, o dicho en palabras kantianas, condición de posibilidad de la síntesis. Justamente la revolución kantiana en el ámbito de la moral iba dirigida a comprender que la ley moral, así como la legalidad última de lo objetivo, no procedía de fuera, sino que era la voz y la invitación que la propia libertad se dirigía a sí misma en el ámbito audible de la conciencia, ligándola con el mundo, a fin de realizarse en él y transformarlo según sus exigencias racionales. Como todo acto, el moral es también el acto de un individuo, pero ese acto le vincula a una forma y ámbito universal, propios de la razón, en cuanto apertura al horizonte universal o total del concepto (Kant diría de la idea), donde todos los modos de ser encuentran su justo acomodo ${ }^{27}$. Si uno se va al fondo racional de sí mismo encuentra allí la fuente del ser y del sentido, su verdadera vinculación con el mundo, con los otros, la apertura al reino de fines en su verdadera y articulada realidad, es decir, tanto del individuo como de la comunidad; la voluntad racional, como también lo piensa $\mathrm{Hege}^{28}$, es una autodeterminación que une ambos momentos. Por eso, la divisa es atreverse a pen-

${ }^{26} F D \$ 137$, anotaciones de Hegel, y $\$ 142$, también en las anotaciones.

${ }^{27}$ "Claramente, le dice Fichte a Jacobi en carta del 30 de agosto de 1795, mi Yo absoluto no es el individuo; eso me lo han atribuido ofendidos cortesanos y filósofos enfadados, para imputarme falsamente la vergonzosa doctrina del egoísmo práctico. Sino que el individuo ha de ser deducido el Yo absoluto. Para ello la Doctrina de la Ciencia pasará sin dilación al derecho natural" (GA III/2, 392).

${ }^{28} F D \$ \$ 7$ y $21-28$. Lo que se dice en esos párrafos sobre la voluntad libre cuadraría más con la posición kantiana, sólo que para Hegel representa su posición frente a Kant, y a éste lo coloca en la figura anterior, la del libre albedrío ( $\$ 12-20$; véase sobre todo $\$ 15$, W VII, 67). 
sar, es decir, a actuar desde sí, a partir de ese ser originario descubierto, darse forma y límite conforme a ese modo de ser. Para Hegel, por el contrario, es la certeza, vacía de verdad, de nuestra autoconciencia lo que hallamos en ese campo, y esto nos impulsa hacia fuera para llenarnos de ser, de sentido, y encontrar una guía racional, pues el vacío es incapaz de darse contorno, límite, concreción.

Esa es la diferencia: la conciencia moral kantiana es voluntad legisladora, verdaderamente autónoma, del individuo y de la comunidad, mientras que la hegeliana es la conciencia particular del individuo, su mero acto individual de querer y decidir, "que, en cuanto esta voluntad, no tiene ningún contenido propio" ${ }^{29}$. Por tanto para Hegel debe obedecer y estar sometida a lo universal legislado, lo único que le otorgará verdad y universalidad, pues también lo universal necesita la convicción subjetiva para ser llevado a la realidad efectiva y mantenerse en ella. La subjetividad moral sólo tiene el derecho de saber a qué se somete, $y$ en concreto que se somete a lo que es racional ${ }^{30}$. Tiene el derecho a quererlo desde sí, como siendo su propia esencia; en eso consiste su autonomía, pues "la verdadera conciencia moral es formal, es decir, presupone los deberes" ${ }^{31}$ como ya dados. El sujeto no tiene derecho de decisión o legislación, sino derecho de comprensión, aquí de comprensión del bien. La libertad moral y su conciencia en Kant (y Fichte), por el contrario, aunque se han separado ciertamente del contenido empírico, no ha sido para irse al vacío, sino para adquirir distancia de lo inmediato y tomar conciencia de la acción originaria de su modo de ser, y es, por tanto, una conciencia sintética de sí, de su realidad y de su idealidad o conciencia. El sujeto moral en Hegel, separado de todo, es mera idealidad ${ }^{32}$, conciencia desgraciada, analíticamente seccionada por el movimiento pendular del método dialéctico. En su mera reflexión se distancia de todo lo existente, tachándolo de insatisfactorio, y se refugia en una interioridad que volatiliza toda determinación de derechos y deberes: «ese es el punto fundamental donde se está, y la enfermedad de esta época»" ${ }^{33}$. Al final la conciencia moral queda rebaja-

${ }^{29} F D \$ 137, \mathrm{~W}$ VII, 254.

${ }^{30}$ Eso es ya ciertamente casi coincidente con Kant, si pusiéramos el acento en esta parte. Pero la cuestión es saber dónde se halla esa racionalidad.

${ }^{31} F D \$ 137$, anotaciones de Hegel.

32 "Conciencia moral como el determinar - un para-sí, forma infinita sin contenido, actividad, idealidad, inquietud, no teniendo ni permitiendo nada fijo- el bien en sí, lo que es, eterno, inmutable - un contenido infinito sin forma, y por eso ningún contenido [se entiende que concreto]" (FD $\$ 141$ anotaciones de Hegel, W VII, 287-288).

${ }^{33} F D \$ 138$ anotaciones. 
da en Hegel a Espíritu subjetivo, a mera opinión casi sin derechos, «por eso la conciencia moral se encuentra sometida a este juicio de si es verdadera o no [...] Por consiguiente, el Estado no puede reconocer a la conciencia moral en su forma propia [la delineada por Hegel, claro está], esto es, como saber subjetivo, del mismo modo que en la ciencia no tienen validez la opinión subjetiva, ni la aseveración de una opinión subjetiva ni la apelación a ella» ${ }^{34}$.

La moral hegeliana se apoya en la idea de bien, un bien objetivo, comprendido como la esencia de la voluntad, porque ésta tiende por naturaleza al bien ${ }^{35}$, pero que no surge como tal de ella - mero autodeterminarse formal--, sino que lo tiene fuera de sí como verdad y contenido ${ }^{36}$. La libertad del sujeto es para Hegel pura negatividad respecto a cualquier contenido, por eso es abstracta ${ }^{37}$. Kant, por el contrario, no comienza su $K p V$ con el bien, con la analítica de los conceptos, sino con la libertad y su ley moral (analítica de los principios), pues ése es el contenido por antonomasia, contra el cual nunca se puede ir, es decir, que no puede ser utilizado como simple medio para otra cosa, y que sin embargo marca el fin de todo lo demás. Ella es la fuente primaria del bien, porque es la fuente última del sentido y de los fines, ya que, lejos de constituir un vacío, es el modo más originario de ser. No es el bien el que determina la libertad, sino a la inversa - sabiendo que hablamos de una libertad racional, es decir, de una correctamente entendida y afirmada en su específico modo de ser-; no hay que hacer el bien por el bien, o ser bueno por ser bueno, sino ser libre porque ahí nos va el ser o no ser. En consecuencia, el sujeto moral en Kant debe constituirse en el legislador, en el forjador de los justos vínculos morales, sabiendo que ese sujeto es tanto individual como comunitario, y no lo uno sin lo otro, pues mi libertad afirma la de todos y a la in-

${ }^{34} F D \$ 137$ A. Hegel era, cómo no, consciente también de que podía suceder lo contrario: "Yo puedo equivocarme, pero las leyes y los regentes también" ( $F D \$ 131 \mathrm{Z}$ ).

${ }^{35} F D \$ \$ 130$ y 133 . «La voluntad subjetiva sólo tiene valor y dignidad en la medida en que su visión (Einsicht) e intención es conforme al bien" ( $F D \$ 131)$.

36 "El infinito autodeterminarse de la voluntad constituye lo formal de la misma» ( $F D \$ 108$ ). Estamos en el punto de vista de la conciencia, es decir, de la escisión sujeto-objeto, forma-contenido. "El deber ser es expresamente argumentado y fundamentado en el carácter formal de la subjetividad, por el que la voluntad subjetiva tiene fuera de sí el objeto, aunque se relaciona constitutivamente con él" (Gabriel Amengual, La moral como derecho. Estudio sobre la moralidad en la Filosofía del Derecho de Hegel, Trotta, Madrid, 2001, p. 184). "El carácter formal de la voluntad consiste en que la voluntad es el puro querer, el puro acto (formal) de querer, prescindiendo de cuál sea su objeto" (Amengual, o. c., p. 193). Pero para Kant, su objeto primero es la misma libertad, y por tanto no está fuera y separada de ella misma; por eso puede ser autonomía.

${ }^{37}$ FD $\$ \$ 25$ y 106. 
versa. Sólo así se la afirma en su correcto modo de ser no cósico, como podemos leer por ejemplo en el siguiente texto: «todo ser racional, como fin en sí mismo, ha de poder considerarse, en relación a todas las leyes a que pueda estar sometido, al mismo tiempo como legislador [...] ha de tomar sus máximas siempre desde el punto de vista de él mismo, pero a la vez del de todos los demás seres racionales como legisladores, que por eso se llaman también personas. $Y$ de esa manera es posible un mundo de seres racionales (mundus intelligibilis) como reino de los fines, y en concreto mediante la propia legislación de todas las personas como miembros $)^{38}$.

La posición kantiana es que la libertad no se opone al bien moral, sino que ella es el bien moral, la fuente primordial del mismo. La libertad kantiana no está enfrentada al concepto, sino que ella misma es el origen del concepto y su finalidad. Es cierto que puede obrar contra sí, negarse, que puede hacer el mal moral, pero en este caso no se rebela en contra de una ley externa, sino contra sí misma. Por el contrario para Hegel el orden ético es objetivo, la objetivación del concepto, no procede propiamente de la subjetividad, sino que ésta se lo encuentra y tiene que obedecer, o como mucho ella es su instrumento de objetivación. La figura de la Moralität está aún en un dualismo que Kant supera, pues él encuentra la ley en el interior mismo de la libertad, y en eso consistiría el vuelco copernicano. También lo ha comprendido así Hegel: en la eticidad se unen los dos, la libertad del individuo y la ley moral objetiva ${ }^{39}$; pues bien, eso es lo que está pensado Kant por imperativo categórico como fuente última, no como desarrollo global de lo ético, claro está (para esto último se necesita la antropología moral).

La síntesis de moralidad y legislación, que estaría más cerca del sujeto kantiano, la circunscribe Hegel a la conciencia heroica, fundadora de Estados. En el estado de naturaleza, cuando aún no se ha formado el Estado, los héroes tienen el derecho de ejercer con los otros lo que Hegel llama una «coerción pedagógica»

${ }^{38}$ Kant, Fundamentación de la metafisica de las costumbres, cap. 2, Ak.-Ausg. IV, 438. Fichte, por su parte, afirma: «en lo que respecta al contenido de la ley, no se exige otra cosa que la absoluta autonomía, la absoluta indeterminabilidad respecto a cualquier cosa exterior al Yo. En consecuencia, la determinación material de la voluntad según la ley es tomada únicamente de nosotros mismos; y toda heteronomía, todo préstamo de los fundamentos de determinación por parte de cualquier cosa fuera de nosotros, es directamente opuesta a la ley" (Etica de 1798, FW IV, $56=$ GA I/5, 67).

39 "Los deberes son relaciones vinculantes con la eticidad substantiva -pero ella es mi esencia, tiene existencia por mí mismo- Su existencia [...] es también mi derecho, es la existencia de mi libertad" ( $F D \$ 155$, anotaciones de Hegel). 
y, por medio de ella, fundar un Estado, obligando a los demás a acatar esa voluntad suya particular, habitada y dirigida en el fondo por la Idea, como Teseo hizo con Atenas según el mito. Pero una vez configurado dicho Estado, ya no hay lugar para esos héroes ${ }^{40}$. Ciertamente "todo lo que surge en la eticidad es producido por esa actividad del espíritu ${ }^{41}$, del sujeto moral, decía Hegel a sus oyentes, y en eso venía a coincidir con Kant, pues ¿̇de dónde iba a salir esa segunda naturaleza como objetivación de la libertad, sino del concepto y la razón que constituye el fondo del sujeto y que Kant denomina libertad y razón práctica? Pero para Hegel este proceso no se sitúa en la abstracción de la conciencia reflexiva individual (entendimiento); no es ella la que hace el Estado, sino el Concepto. Y por consiguiente, una vez que se ha configurado en un ethos del pueblo, el individuo tiene que atenerse a él y ser un buen ciudadano. La publicidad y el conocimiento de las leyes estatales y de las costumbres nos liberan de la contingencia de las opiniones subjetivas ${ }^{42}$. Los individuos son entonces accidentes de esos poderes éticos ${ }^{43}$, y sólo aceptándolos con disposición de ánimo moral, la persona deja de ser un mero accidente de esa substancia ética ${ }^{44}$. Los individuos pueden tener una fuerza configuradora de lo ético únicamente en circunstancias extraordinarias, cuando las relaciones comunitarias entren en verdaderas colisiones, o cuando aún no se haya configurado el Estado ${ }^{45}$. "Sólo en los tiempos en los que la realidad efectiva es una existencia vacía, carente de espíritu y de compostura, puede estarle permitido al individuo retirarse de la vida efectiva a la interior ${ }^{46}$, como hiciera Sócrates o los estoicos, hombres con una voluntad superior a la de su tiempo, o sea, con un contenido moral más elevado que la eticidad de entonces. ¿Pero no ocurre eso en mayor o menor medida cuando queremos criticar alguna costumbre o ley positiva?

En Kant el individuo también tiene que obedecer a las leyes del Estado ${ }^{47}$, pero ha de guardar en sí el coraje y la valentía de pensar y actuar racionalmente

\footnotetext{
${ }^{40} F D \$ 93$ y $\mathrm{Z}$ y $\$ 102$.

${ }^{41} F D \$ 138 \mathrm{Z}$.

${ }^{42} F D \$ 132 \mathrm{~A}$.

${ }^{43} F D \$ 145$.

${ }^{44} \mathrm{Enz} \ 514$.

${ }^{45} F D \$ 150 \mathrm{~A}$.

${ }^{46} F D \$ 138 \mathrm{Z}$. Véase también $\$ 138 \mathrm{~A}$.

${ }^{47}$ Kant piensa también que la mejora moral depende de las instituciones racionales legales (Ak.-Ausg. VIII, 366).
} 
siempre desde él mismo, con libertad de críticas, de ideas y de expresión de las mismas, y, podríamos nosotros añadir, de asociación para el cambio de la política. El sujeto no vacío de Kant tiene, por ello mismo, más soporte real y más fuerza legisladora, participativa y democrática, configuradora de lo público y de lo privado. Guarda por eso mayores similitudes con el Gewissen o «buena conciencia» que, en el texto de la Fenomenología, Hegel contrapone a la "conciencia moral» (moralisches Bewußtsein) calificada de abstracta, pues aquélla «tiene en la certeza de sí el contenido para el deber anteriormente vacío, así como para el derecho vacío y la vacía voluntad universal ${ }^{48}$ de la conciencia moral que Hegel atribuye a Kant. La universalidad de esa buena conciencia no es abstracta, pues está mediatizada por "el momento del ser reconocido por los otros" ${ }^{49}$. Pero eso también lo encontramos en Kant, primero en el concepto de respeto (Achtung), que es el reconocimiento práctico, real, en la acción y no sólo en el pensamiento, de la libertad en mí y en los otros ${ }^{50}$, y, segundo, en el concepto más amplio de «reino de fines", que incluye tanto un Estado legal y político, con sus proyectos para la paz, como un Estado o comunidad ética, «un reino de Dios sobre la tierra ${ }^{51}$, donde «el perdón y la reconciliación» llegarían a su plenitud.

\section{La acusación de formalismo y su imposible concreción}

Debido a ese vaciamiento, la segunda antinomia en la que cae la conciencia moral kantiana según Hegel reside en que carece de un principio de determinación que nos pudiera indicar los diversos deberes y derechos concretos; sólo es capaz de presentar la existencia del deber en general. Si en el punto 2 mirábamos a la "parte ante", al fundamento ontológico de la ley moral, en este punto 3 hemos de girarnos hacia la "parte post" de la misma.

Vimos que para justificar su intención en el obrar y resolver las dificultades de su aspiración al bienestar, el sujeto busca aquí, en el tercer momento de la Morali-

${ }^{48} F E$, W III, 466, trad. 370. «El espíritu cierto de sí, en el que lo en-sí ha adquirido el significado del Yo consciente de sín (o.c. W, 472, trad. 375).

${ }^{49}$ FE W III, 470, trad. 373.

${ }^{50} \mathrm{Y}$ si reflexionamos sobre el ser no meramente formal de la libertad, a su afirmación la podremos llamar amor práctico, que, si bien es acción, no dejará de producir resonancias afectivas al concretarse, y será, por consiguiente, una fuente de felicidad, aunque no en el sentido kantiano de este término.

${ }^{51}$ Sobre este punto véase La Tercera parte de La religión dentro de los límites de la mera razón. 
tät, apoyarse en un bien (moral) universal. Sin embargo, toda acción real requiere un fin determinado, y al sujeto en su vida cotidiana no se le presenta el bien en esa abstracción universalista, sino una multiplicidad de acciones concretas, de obligaciones y de posibilidades de actuación, muchas veces en pugna entre sí, de modo que él ha de saber orientarse y decidir en cada circunstancia. Pero debido a la generalidad abstracta en la que aquí se presenta, el bien no ofrece un criterio para esa concreción. A esta altura de la génesis del Espíritu objetivo, a todo lo más que se llega es a determinar moralmente el deber de cumplir con el derecho y procurar el bienestar propio así como el de todos los demás en esa determinación universal ${ }^{52}$. Pero ni siquiera esas determinaciones han surgido del concepto del deber, sino que ya estaban dadas previamente, y el único contenido del mismo es la universalidad abstracta, la identidad formal y carente de contenido ${ }^{53}$. El sujeto se ve obligado a decidir, mas como se ha quedado vacío (acabamos de discutir ese punto), dicha decisión subjetiva abre la puerta a lo arbitrario, a lo contingente y al mal moral. Para evitar esto, sería preciso que el sujeto recurriera a los deberes y derechos que ya encuentra en la sociedad histórica en la que vive, y una vez fundado el deber moral en su íntima esencia racional, pasara a darle contenido en la eticidad.

El único criterio al que podría recurrir ese sujeto kantiano es al principio de no contradicción. Entonces, si lo aplica al contenido a fin de juzgar su valor moral, el criterio es que ha de poder ser universalizable, que pueda recorrer coherentemente toda la multiplicidad de casos y sujetos sin sufrir modificación. Y aquí se inicia la acusación de vacío formalismo contra el imperativo categórico. La ley moral no pasa de ser una mera forma, una simple exigencia de identidad, se dice, y no llega a ningún principio determinante del contenido en cuanto tal. La conciencia moral, pura certeza de sí, es incapaz de darse otro contenido a sí misma. "Lo universal, lo que-no-se-contradice, es algo vacío, que en lo práctico así como en lo teórico no llega a ninguna realidad ${ }^{54}$. La identidad tautológica es una exigencia o ley del entendimiento abstracto que no proporciona ningún contenido, o como había dicho Kant, es el primer principio de los juicios ana-

$52 F D @ 134$.

${ }^{53} F D @ 135$.

${ }^{54} H F, \mathrm{~W} X X, 368$. Y sigue diciendo en esa misma página: "Por eso Kant para la determinación del deber [...] no ha tenido otra cosa que la forma de la identidad, la del no-contradecir-se, que es la ley del entendimiento abstracton. Se identifican aquí el principio de identidad y el de no contradicción, que son dos momentos inseparables de una misma acción sintética: ser sí misma, y no ser lo otro de sí. 
líticos, donde no se dirime la realidad efectiva de algo, ni siquiera su cognoscibilidad (el que sea un objeto posible de experiencia, posibilidad transcendental), sino únicamente su pensabilidad (posibilidad de la lógica meramente formal). "Con la identidad no se da un paso más allá, Dios es Dios; todo contenido, puesto en esa forma, está sin contradecirse a sím ${ }^{55}$. Pero para ello es al menos necesario que el contenido venga dado de otra parte, de lo natural o de lo social, pues "alli donde no hay nada, tampoco puede haber contradicción" ${ }^{56}$. "Esa es la carencia del principio kantiano-fichteano, que es enteramente formal. El frío deber es el último leño sin digerir en el estómago ${ }^{57}$ de la moralidad moderna.

Más aún, dado que el sujeto no tiene otro criterio universal que la exigencia de no contradicción, el contenido vendrá determinado por su propia particularidad, pues cualquier contenido puede resistir esa prueba con tal de que lo mantengamos inalterable y que soportemos siempre su presencia. Mas elevar a principio universal esa particularidad de la voluntad natural es justamente una subversión de los principios y la raíz del mal moral ${ }^{58}$; por eso, "esta certeza de sí, poniéndose en su cumbre, aparece en dos formas que pasan inmediatamente la una a la otra, la de la conciencia moral y la del mal moral ${ }^{59}$. La voluntad se ha fugado hacia la vanidad absoluta de un ser bueno inobjetivo, y esa subjetividad abstracta se arroga el derecho de decidir sobre el bien moral, sin ver que esa misma pretensión es el principio del mal moral ${ }^{60}$. Su consecuencia política se habría mostrado a la luz pública en el período del Terror jacobino de la Revolución

55 Ibídem.

${ }^{56} F D \$ 135 \mathrm{Z}$ (W VII, 254). Esta crítica al aspecto formal y tautológico del imperativo categórico se encuentra ya en el escrito de Hegel de 1802-3 Sobre las maneras de tratar cientificamente el derecho natural (W II, 459 ss.). De igual modo para Kant la existencia no pertenece al orden de los conceptos, y no hay contradicción en la nada. Más aún, no sería contradictorio (pensar) que nada hubiera existido, lo que ya Hegel no aceptaría, aunque sí sería transcendentalmente contradictorio afirmar que nada existe o que el mundo no existe.

${ }^{57} H F, \mathrm{~W} X \mathrm{XX}, 369$.

${ }^{58} F D \$ 139$ y A. Enz. $\$ 509$.

${ }^{59} \mathrm{Enz}, \$ 511$. De ahí la identidad de fondo de los dos títulos que tiene este tercer momento de la moralidad, que la Enz denomina "el bien y el mal" (morales) y la $F D$ uel bien y la conciencia moral».

${ }^{60}$ Enz. $\$ 512$. Si el último criterio de la moral y del derecho es la convicción y la intención de cada uno, sigue diciendo Hegel, entonces nada será malo moralmente, pues todos sabrán encontrar una buena intención en todas sus obras, y los otros podrán hacer lo contrario guiados por sus convicciones (FD $\$ 140$ ). La subjetividad es el principio del caos y de la arbitrariedad, al contrario de lo que habia buscado Kant en su nivel transcendental. 
Francesa, con el que Hegel asocia la posición moral de Kant y Fichte ${ }^{61}$. Sin criterios objetivos y objetivados, cualquier iluminado puede venir a imponer universalmente su opinión errada, su voluntad particular, disfrazándola de bien moral. Ese momento negativo y de indeterminación de la libre voluntad puede convertirse en la furia de la destrucción, en el fanatismo que quiere hacer tabla rasa de todo orden social ${ }^{62}$. Por la muerte, esa libertad individual absoluta se da cuenta de su carencia de positividad, «el terror de la muerte es la intuición de esa su esencia negativa ${ }^{63}$; de ella no se puede sacar un principio de organización social. Kant usa preferentemente el término de moralidad, y con razón, «pues los principios prácticos de esa filosofía se limita enteramente a ese concepto, y hasta hacen imposible el punto de vista de la eticidad, a la que incluso aniquilan y ofenden expresamente" ${ }^{64}$. Sólo la eticidad hegeliana, el acatamiento consciente de un bien objetivado en las leyes de un Estado racional, pone coto a tal barbarie. Esa es "la verdadera conciencia moral " ${ }^{65}$. Pero que la conciencia concreta de un individuo coincida con ella, eso ha de ser juzgado por el contenido de derechos y deberes presentes en la eticidad, pues la verdadera conciencia moral sólo se halla contenida en la disposición de ánimo ética ${ }^{66}$, y esa disposición es la confianza ${ }^{67}$. Hay que descubrir que el universal no es simple no-contradicción subjetiva, sino una fuerza real que se objetiva y particulariza y crea para sí «una segunda naturaleza ${ }^{68}$ en el mundo de la familia, de la sociedad civil, del Estado y de la historia universal. La Idea, como el Logos estoico, es lo que allí se realiza, y sabio es aquel que reconoce esa rosa en la cruz del presente y la acata ${ }^{69}$.

${ }^{61}$ Es bien conocido que los dos primeros escritos políticos de Fichte, Reivindicación de la libertad de pensamiento a los Principes de Europa que hasta abora la oprimieron, pero sobre todo Contribución a la rectificación del juicio del público sobre la Revolución Francesa, ambos de 1793, dieron fama a Fichte de jacobino.

${ }^{62} F D \$ 5$.

${ }^{63} \mathrm{FE}, \mathrm{W}$ III, 437.

${ }^{64} F D \$ 33$, W VII, 88. La mayor parte de los intérpretes de Hegel han protestado de ese exceso combativo hegeliano. Yo creo, sin embargo, que es una consecuencia coherente a su planteamiento, es decir, a todos nos es claro que ese juicio no conviene a Kant, y sin embargo se adecua plenamente a las figuras hegelianas que encontramos en el momento de la Moralität. Y esa es justamente mi tesis: estas figuras no se compadecen con la posición kantiana, o sea, ahí no encontramos una interpretación y crítica correctas de Kant.

65 "Das wahrhafte Gewissen" (FD\$137, W VII, 254).

${ }^{66}$ FD $\$ 137 \mathrm{~A}$.

${ }^{67} \mathrm{Enz} . \$ 515$.

${ }^{68} F D \$ 4$; véase también $\$ 142$.

69 "¿Qué es eticidad? Que mi voluntad sea puesta como conforme al concepto, que su subjetividad sea superada (aufgehoben), por tanto a) derecho, el derecho objeto de la voluntad, b) subjetividad, reconocimiento de lo objetivo, concepto" ( $F D \$ 142$, anotaciones de Hegel). 
Creo que aquí Hegel no repara en la especificidad kantiana de lo práctico frente al carácter de lo teórico. No tiene el mismo significado la exigencia de identidad en el ámbito teórico que en el práctico, si bien aquélla remite en última instancia a ésta, y no a la inversa ${ }^{70}$. En lo teórico, con el principio de identidad sólo hemos puesto la acción ideal-idealizante del "Yo pienso», y éste no constituye una acción real ni una relación real con el mundo, sino una relación lógico-transcendental; por ejemplo, cuando yo conozco este vaso, no lo transformo realmente, lo que hago es darle un sentido en la objetividad. La exigencia teórica es mera idealidad, son las formas transcendentales o ámbito ideal que el sujeto abre (su conciencia-autoconciencia) para recibir e interpretar el mundo. Éste es la realidad que él no protagoniza, la que de algún modo le tiene que venir dada, y frente a la cual él se comporta con pasividad real (realismo empírico) y actividad meramente ideal (idealismo transcendental). Tenemos por tanto que concluir que cuando nos quedamos con la mera exigencia ideal no llegamos a ningún contenido, a ninguna realidad; ésa es la conclusión de la Crítica de la razón pura, de su Dialéctica transcendental contra las pretensiones de lo que ella denomina «metafísica dogmática».

Pero no sucede lo mismo en el ámbito de lo práctico, y captar esa diferencia es la puerta que abre el método transcendental hacia la realidad en sí, hacia la realidad de lo libre; esa es "la magnífica apertura» ${ }^{71}$ de la que antes hablábamos. Cuando nos encontramos con una exigencia práctica, enunciada en la ley moral, como es dicha universalidad moral, que es petición de identidad y coherencia en la acción, ella no se queda en ser una mera idealidad que estuviera a la expectativa de contenido, vacía por tanto de toda realidad, sino muy al contrario, en su voz resuena el ser originario, en su exigencia se expresa el modo de ser de la realidad en sí, la de la acción real-ideal de la libertad, que está a la búsqueda de su aceptación, pues todo ello es esencial a su carácter subjetivo. Ése será el contenido último de la moral: sé libre, trata la libertad en ti y en los otros, en todos y en todos los casos (universalidad), según su modo de ser originario, con respeto, no como puro medio para otra cosa, sino a la inversa. Desde ahí construye Kant su Metafisica de las costumbres, el pendant kantiano de la eticidad de

${ }^{70} \mathrm{~A}$ la base del principio lógico de identidad, argumenta Fichte en el $\$ 1$ de su Fundamentación de toda la doctrina de la ciencia, está el acto real-ideal de autoidentificación del Yo consigo mismo, gracias al cual él se constituye, ciertamente no de manera transcendente, cerrada y sin mundo, sino en apertura y distinción con él, o sea, transcendentalmente.

${ }^{71} \mathrm{KpV}, \mathrm{A} 168$, Ak.-Ausg. V, 94. 
Hegel. En consecuencia, no podrá aceptarse ningún otro contenido determinado empírico que contravenga la realidad de lo libre, o incluso que deje de fomentarlo, aunque alguien, en su voluntad particular, ame la esclavitud en cualquiera de sus múltiples formas, también para él, y quiera universalizarla. Todo otro contenido moral tendrá que ser un medio para la afirmación de éste, el único fin final de toda la creación, que deja, ciertamente, un amplísimo abanico de posibilidades en cuanto a organizaciones concretas. De los tres niveles hegelianos de autoconciencia de la voluntad ${ }^{72}$, la voluntad racional kantiana no es ciertamente la voluntad natural ${ }^{73}$, que correspondería a las inclinaciones o predisposiciones naturales en Kant, pero tampoco el mero libre albedrío distante de cualquier contenido, como piensa Hegel ${ }^{74}$, sino más bien la voluntad libre ${ }^{75}$, que "es verdadera, o más bien la verdad misma ${ }^{76}$, y cuyo alfa y omega es la misma libertad ${ }^{77}$.

Y ¿̇por qué, si es el ser originario, se pone a sí mismo su propio ser como contenido o tarea a realizar y no lo tiene ya en sí consumado? De esta última manera es como se ha pensado normalmente lo divino, como siendo ya, desde siempre, la omnitudo realitatis. Pues bien, ésa es la diferencia ontológica entre el pensamiento crítico y el que éste denomina como filosofía dogmática: el ser originario o libertad que alcanzamos a afirmar con el método transcendental no tiene esa forma de omnitudo realitatis, la que recobrará de nuevo en el Absoluto de Schelling y Hegel (así como, a su manera, en la filosofía de Fichte a partir de 1801), sino que se expone como fuente de acción real (e ideal) en pro de su obligada realización en el mundo, pero de manera subjetiva y consciente de sí. Sólo gracias a esa contraposición entre su originariedad y su finitud llega a saber de sí (la conciencia requiere contraposición) y se convierte en sujeto. Más aún, únicamente en esa diferenciación entre el ser como acción y su forma como razón moral o imperativo categórico, en esa tensión del deber-ser - diferenciación que se alcanza en la conciencia reflexiva-, ese ser puede libremente darse a sí mismo su forma, aceptarse y configurarse como sujeto, y sólo así se realiza como libertad. Eso abre indudablemente las puertas a la posibilidad de la no aceptación de

\footnotetext{
${ }^{72} F D \$ 21$.

${ }^{73} F D \$ 10-11$.

${ }^{74} F D \$ \$ 12-20$ y 29 ; véase sobre todo $\$ 15$, W VII, 67.

${ }^{75} F D \$ \$ 21-28$.

${ }^{76} F D \$ 23$, W VII, 75.

${ }^{77} F D \$ 27$.
} 
sí, lo que daría lugar al mal moral, pero la posibilidad de ese mal forma parte del concepto de libertad moral ${ }^{78}$. Al menos podemos decir, con la primera parte de La religión dentro de los limites de la mera razón, que el mal moral es un acto de la libertad, y ese acto es un mal no porque en él la libertad del sujeto no quisiera acatar un bien situado fuera de ella, como lo otro de sí, en lo objetivo universal, como le podría suceder al sujeto moral hegeliano ${ }^{79}$, sino por la posibilidad que ella tiene de negarse a sí misma en cuanto fuente de bien y de sentido, y anularse materialmente, venderse, esclavizarse. Si ella careciera de esa posibilidad, actuaría como una fuerza automática más de la naturaleza. Por consiguiente, el mal moral según Kant no hunde sus raíces en el vacío o carencia de ser y de ley de la libertad subjetiva (transcendental), sino lo contrario, se basa en que la libertad, reconociendo más o menos ${ }^{80}$ su ser originario como guía de la acción - sin lo cual no llegaría a ser moral el mal, como mucho alcanzaría a ser un mal físico-, decide dar prioridad, en una inversión de principios, a otras fuerzas e intereses de su finitud ${ }^{81}$, lo que Hegel llamaría la «naturalidad de la voluntad ${ }^{82}$, es decir, porque siente en sí la fuerza de distintas instancias de realidad, aunque con cierto grado de ausencia.

${ }^{78} \mathrm{Al}$ menos esa posibilidad del mal está ínsita en la libertad del hombre. La otra, la voluntad santa de Dios, no pasa de ser una hipótesis y un desideratum moral. Sobre estos asuntos me he extendido más en el capítulo 9 de mi libro El punto de partida de la metafisica transcendental. Un estudio critico de la obra kantiana (UNED, Madrid, 1993).

79 "La autoconsciencia finita es formal. Ahí radica su constitución en escisión y en relación entre sujeto y objeto, forma y contenido. La subjetividad finita como tal es inacabada en su ser; en cuanto algo escindido, está abocada constitutivamente a su otro. Pero ahí mismo radica su distancia: la autoconciencia, en cuanto formal, no está vinculada al contenido, se encuentra frente al contenido. Formalidad significa que la autoconsciencia no es inmediatamente ni uno ni otro contenido. De este constitutivo carácter escindido de la autoconsciencia se sigue su posibilidad de ser reflexiva, de ser mala. Al mismo tiempo la formalidad de la autoconsciencia significa que ella es omnicomprensiva, que sólo en lo otro puede volver a sí misma. [...] La formalidad es la presencia de la subjetividad; es el "yo quiero" que acompaña y que debe poder acompañar en todo momento al orden ético. La formalidad es indispensable para que el orden sea ético, y no puramente administrativo u organizativo, legal, o pura costumbre. Pero en la medida en que la formalidad se cierra en sí misma [contrapone su propia particularidad a la universalidad real y objetiva] y no asume lo otro de sí -en este caso, el orden ético objetivo universal-, ella se pervierte, se convierte en mala" (Amengual, o. c., p. 341).

${ }^{80}$ Kant habla de tres niveles del mal moral o tres grados de propensión al mal: la fragilidad, la impureza y la malignidad (Religion, Ak.-Ausg. VI, 29-30, 37, 44).

${ }^{81}$ En su conocido artículo sobre "¿Qué es Ilustración?", Kant resalta el miedo y la pereza.

${ }^{82} F D \$ 139$ A (W VII, 261). 
La experiencia más originaria del sujeto transcendental no es la objetiva, sino la de la libertad (Kant habla de la primacía de lo práctico), y sólo de ese ser originario puede hablarse con pleno fundamento, mientras que de la inmortalidad y de Dios ni siquiera alcanzamos a conocer su posibilidad ${ }^{83}$, sólo cabría un desideratum $^{84}$ y la apuesta -o incluso quizás la "experiencia" - moral de un ordo ordinans en la acción, que a mi modo de ver podría ser interpretado de forma distinta a la de la tradición cristiana, a la que se acogió Kant. Pues bien, esa realidad en sí no es la del vacío o la de la mera forma sin contenido, pero tampoco la de la omnitudo realitatis, de modo que el camino crítico se muestra aquí también, al igual que en las palabras finales de la $\mathrm{Kr} V$, como el único intermedio practicable, el propio del sujeto racional finito. Casi todas las contradicciones que ve Hegel en la moralidad kantiana (y fichteana) están construidas desde esa exigencia ontológica del hen kai pan, de un Absoluto que ni Kant ni el Fichte de Jena pretendieron poner a la base de sus filosofías, sino que rechazaron como dogmática y contraria a la subjetividad libre. Con toda evidencia, ningún ente es adecuado a esa petición de infinita totalidad, bien consciente es de eso Kant en las dialécticas de sus tres Críticas ${ }^{85}$. ¿Lo sería finalmente la propia filosofía de Hegel? Más aún, ¿es un infinito real una exigencia ontológica necesaria y aceptable? El propio sistema de Hegel está construido desde ella, y naturalmente la vuelve a dar como resultado, de modo que sólo se prueba a sí misma en su previa aceptación como criterio último de realidad y racionalidad. Por ejemplo, únicamente en virtud de tal presupuesto el progreso indefinido de la acción moral en Kant y Fichte puede ser calificado de mala infinitud ${ }^{86}$, aunque en verdad sea lo único que podemos realizar y conocer, incluso en la eticidad hegeliana y su procesualidad histórica ${ }^{87}$. ¿No es todo lo real necesariamente finito, y

${ }^{83}$ Kant, KpV, Prólogo, A 4-6, Ak.-Ausg. V, 3-4.

84 "El hombre honrado bien puede decir: yo quiero que exista un Dios" (Kant, KpVA 258, Ak.-Ausg. V, 143).

85 «Por una idea entiendo una perfección a la cual nada dado en la experiencia puede serle adecuado" (Kant, Kp V A 230 nota, Ak.-Ausg. V, 127).

${ }^{86}$ Véase por ejemplo Enz. $\$ \$ 94-95$ con su A (nota).

${ }^{87} F D \$ 3 Z$ (W VII, 42-43). En el inicio colocan Kant y Fichte la libertad moral que se busca a sí misma; en el punto omega, el sumo bien realizado, a lo cual nunca llegará: «El último fin final del hombre es someter a sí mismo todo lo irracional, dominarlo libremente y según su propia ley. Este fin final es completamente inalcanzable [porque el hombre seguirá siempre siendo un ser sensible y finito] [...] Por consiguiente, no es el destino del hombre alcanzar esta meta. Pero puede y debe aproximarse a ella cada vez más, y por tanto, la aproximación infinita a esta meta constituye su vocación, su verdadero destino como hombre, o sea, en cuanto ser racional 
sólo a ese precio puede saberse real y hacerse efectivamente real, de modo que lo infinito es meramente ideal en el sentido de que sólo lo ideal puede quedar ilimitado? En todo caso, el tener que satisfacer las necesidades materiales y el inevitable antagonismo entre los individuos (también en sus aspectos psicológicos, por no hablar del mal moral) hacen que la libertad nunca pueda ser realizada plenamente en el plano político, por tanto tampoco en el moral, y que jamás abandone enteramente el momento del deber-ser, que es lo que piensa Kant. El Espíritu objetivo, al igual que el subjetivo, no es aún infinito, absoluto, sino finito, $y$ "su efectiva racionalidad conserva en ella el lado del aparecer exterior" ${ }^{88}$, de cierta exterioridad no resuelta aún plenamente en la Idea, de modo que, siguiendo la lógica de la esencia, el Espíritu objetivo no es ciertamente apariencia (Scheinen) sino fenómeno (Erscheinung), pero no aún manifestación (Manifestieren) de la Idea, pues él no termina de superar toda escisión y no logra una plena identificación entre la esencia y su manifestación.

Ahora bien, si la libertad no es la omnitudo realitatis se habrá de enfrentar a su finitud, y ésta le impondrá contenidos empíricos. Evidentemente desde la sola

pero finito, en cuanto ser libre pero sensible" (Fichte, Algunas lecciones sobre el destino del sabio, FW VI, 299-300, trad. de Faustino Oncina y Manuel Ramos, Istmo, Madrid, 2002, p. 59). Debido a nuestra finitud real, en el nivel de la acción práctica estamos siempre en camino, en tensión y en posibilidad de involución, incluso en el terreno de la eticidad hegeliana; aunque aquí la fe en el progreso de la Idea es constitutiva y no meramente regulativa, como en Kant, ninguna figura histórica del Espíritu objetivo será plenamente adecuada a ella. Pero entonces no es ahí donde podemos encontrar la plenitud. Tendremos que irnos a otro registro, sin por ello abandonar éste del que no podemos salir, sino uniendo el saber objetivo con la acción libre y el sentimiento de sí ( $L e$ bensgefuihl). Indicaciones al respecto fueron recogidas en la Critica del Juicio: el juego desinteresado en lo estético, el sentir de las raíces en la naturaleza subjetiva o teleológica, o lo divino que en ello también se refleja. Ése es el camino que iniciaron los románticos. En todo caso, la eticidad hegeliana es también un ámbito fragmentado, wen el que la libertad no se realiza totalmente, precisamente porque es el reino de lo objetivo, que como tal se encuentra siempre enfrente del sujeto, sin llegar a una verdadera unidad" (Amengual, o. c., p. 387), por lo cual se hace necesario pasar a otra esfera donde la plenitud sería propiamente captada según Hegel: el arte, la religión y sobre todo la filosofía. Esta última es contemplación que nos reconcilia con la realidad, sin por ello hacernos pasivos, pues a Hegel le caracteriza la crítica de toda interioridad que no se hace obra exterior, como por ejemplo la objeción que en este ámbito de la moralidad pone al alma bella: "le falta la fuerza de la enajenación, la fuerza de convertirse en cosa y soportar el ser. Vive en la angustia de manchar la gloria de su interior con la acción y la existencia, $[\ldots$ y renuncia a] transformar su pensamiento en ser y confiarse a la diferencia absolutan ( $F E$ W III, 483-484, trad. 384). En eso Hegel tiene indudablemente una enorme fuerza educadora frente a ensoñadoras fantasias, aunque tampoco cabe nivelar por ello todas las ensońaciones.

${ }^{88}$ Enz. $\$ 483, \mathrm{~W} \mathrm{X}, 303$. 
ley moral, en la cual hemos hecho abstracción de esos contenidos, no será posible averiguar cuáles son éstos, pero tampoco se pretendía; lo empírico ha de ser dado, y desde la simple ley moral o libertad no será posible saber, por ejemplo, que es preciso comer, o dormir, o hacer ejercicio, o ir al banco para sacar dinero, etc. Lo que sí se pretende es poder determinar qué contenido es moral, cuál es obligado y cuál es permitido, una vez que están dados, qué acción es un deber; ése era también el sentido de la pregunta de Hegel acerca de la especificación del bien. Con la ley moral lo que tenemos es un criterio para valorar las acciones en orden a la libertad. En efecto, desecharemos los contenidos o acciones cuyas máximas no se compaginen con esa exigencia de identidad y de realidad que tiene la libertad, ya sea en su acción inmediata o en su apoyatura empírica (por ejemplo la salud de mi cuerpo). Según eso habrá acciones más o menos necesarias por cuanto que sean más o menos imprescindibles para respetar o fomentar esa libertad de todos. El sistema concreto de fines tendrá que echar mano de la experiencia empírica, por tanto de lo antropológico y lo cultural o histórico, a fin de ir valorando moralmente esa multiplicidad y no quedarse en una aceptación acrítica de la eticidad reinante. Pero también, y primariamente, una ética tendría que explicitar las condiciones necesarias para el desarrollo de la libertad de los seres racionales finitos ${ }^{89}$. En consecuencia, no todo contenido cabe moralmente, y menos una política del terror, donde se elimina toda base a la libertad y al respeto del otro, por no hablar del respeto a la propia libertad.

Como anteriormente dije, en la $K p V$, en sus primeros parágrafos, se deduce la ley moral haciendo abstracción de cualquier contenido, pero se trata de todo contenido exterior a la acción misma, a la propia libertad, no de ella como ser. Aunque quizás Kant (o bien su recepción) no haya explicitado esto suficientemente y pudiera sostenerse que esto no aparece con claridad en la letra de su obra, se impone que nosotros reflexionemos sobre lo que ahí quería ser pensado. Es cierto que en esta segunda Crítica Kant primó la universalidad en su aspecto formal, preocupado como estaba por encontrar «una fórmula que determine con total exactitud y sin error lo que se ha de hacer para cumplir una tarea ${ }^{90}$, pero no dejó de considerar a la libertad como su ratio essendi, acción real y puerta de entrada a la realidad no sensible, aquella realidad, que por su dignidad ontológi-

${ }^{89}$ Algo de eso hacen Kant en su Metafisica de las Costumbres, Segunda Parte, y Fichte en su Ética de 1798, en su segundo Capítulo y las dos primeras Secciones del tercero.

${ }^{90}$ Kant, Kp VA 14 nota, Ak.-Ausg. V, 8. 
ca, se presentaba como fin en sí misma, alfa y omega de todo otro interés y acción. Este aspecto ontológico y no meramente formal quedaba, ciertamente, más claro en la segunda y tercera fórmula del imperativo categórico de la Fundamentación de la metafísica de las costumbres, que exponían al ser racional como fin en sí y legislador universal en un reino de fines. Pero cuando pensemos la universalidad de la ley moral no podemos interpretarla como si fuera algo de naturaleza meramente lógica, desgajándolo del contexto en donde se inserta, de la acción real y en sí de donde parte en cuanto autoafirmación de la libertad, pues, como resalta el mismo Hegel del pensamiento moral kantiano, "para la voluntad no hay otro fin que el creado a partir de ella misma, el fin de su libertad» ${ }^{9}$.

Podríamos, y deberiamos como antes decia, analizar más detenidamente la acción de la libertad subjetiva, comprender que, para ser subjetiva, requiere también la finitud, y veríamos entonces que de ella cabría deducir muchos "contenidos". Por esa finitud que presupone, ella implica la existencia de otros seres racionales, de un mundo material, de una causalidad sensible en él por parte del sujeto, por tanto de un cuerpo subjetivo propio, de una propiedad, etc, aspectos que va analizando, por ejemplo, Fichte en su Filosofia del derecho natural de 1796 o en su Ética de 1798. Ya la misma universalidad de la ley conlleva por su parte no sólo la multiplicidad de actos de un mismo individuo, sino de nuevo, como se ha dicho, una pluralidad de seres racionales en interacción de respeto práctico o reino de fines ${ }^{92}$, así como la publicidad de la máxima moral seguida ${ }^{93}$, lo cual destruiría la soledad de una intimidad individual, cerrada y monadológica en la que Hegel coloca a su sujeto moral en cuanto voluntad en definitiva particular. Por cierto que en dicha Ética fichteana, en su $\$ 9$, encontramos ya la misma objeción contra Kant, de que

${ }^{11}$ Hegel, $H F \mathrm{~W}$ XX, 367.

92 "Todos los demás sin mí no serían todos y, por consiguiente, la máxima no tendría en sí la universalidad de una leyn" (Kant, MS Ak.-Ausg V, 451)

${ }^{93} \mathrm{Si}$ se hiciera pública y conocida la máxima de mentir y de no cumplir la palabra dada, esa promesa se destruiría a sí misma "porque sería vano fingir a otros mi voluntad respecto a mis futuras acciones, pues no creerían ese fingimiento" (Kant, FMC cap. 1, Ak.-Ausg. IV, 403), y en eso consiste el criterio de su (no posible) universalización. Lo mismo ocurre en el derecho: "Si abstraigo de toda materia en el derecho público [...] sólo me queda la forma de la publicidad [...] Toda pretensión en derecho ha de tener esa capacidad de publicidad, y por tanto ésta puede [...] proporcionar un criterio, fácil de usar y que se encuentra a priori en la razón, para conocer enseguida y en último caso, como por un experimento de la razón pura, la falsedad (su ser contrario a derecho) de la pretensión pensada (praetensio iuris)" (Kant, Por la paz perpetua, el último punto, Ak.-Ausg. VII, 381). 
"si únicamente se mira a la facultad superior de desear, se obtiene simplemente una metafisica de las costumbres, que es formal y vacía. Sólo mediante la unión sintética de esa facultad con la inferior se obtiene una ética, que ha de ser real ${ }^{94}$. Y en el parágrafo siguiente distingue Fichte la libertad formal de la material en un sentido muy similar a Hegel. Encontramos, pues, aquí una de sus fuentes, de modo que Hegel utiliza las mismas armas de Fichte para ir contra éste.

\section{El dualismo entre el deber y el mundo}

La tercera antinomia que encuentra Hegel en la moralidad Kantiana es la dialéctica entre felicidad y virtud. En el principio de la moralidad, la atención está puesta sólo en aquella acción por la que ingresamos en esa esfera, a saber, la libertad, y no se atiende a la felicidad o bienestar. Sin embargo hemos visto en el primero de los artículos que la felicidad forma parte del fin moral como uno de los ingredientes necesario del ser humano libre. Ambas, felicidad y virtud, deben armonizarse, pero al menos al nivel humano es contingente que así suceda. Por esa necesidad de síntesis entre ellas, Kant postula la existencia de Dios. Podríamos comprender ese postulado, tendente a resolver la cuestión de la esperanza y del sentido último de la vida, como una pieza precrítica y cristiana que no ha sido suficientemente elaborada desde el nuevo paradigma del método transcendental, y pensar lo divino según otro modo de ser no teísta, debido a los problemas que esta hipótesis acarrea ${ }^{95}$. Por ejemplo, un Dios infinito no podría alcanzar la conciencia de sí, debido justamente a que su infinitud real no le permitiría contraponerse realmente a lo otro. Además, su omnipotencia sería incompatible con la libertad del sujeto finito ${ }^{96}$, de modo que, al ser una solución tan potente y masiva, destruiría aquello mismo que pretende garantizar. Algo parecido po-

${ }^{94} F W \mathrm{IV}, 132=\mathrm{GA} \mathrm{I} / 5,126$. Véase también el $\$ 12$, donde además el imperativo categórico es interpretado como expresión de un impulso puro dirigido a la absoluta independencia que, si no forma una síntesis con el impulso natural, tendría como consecuencia la destrucción de todo límite, o sea, la negación de toda objetividad o mundo.

95 Un ensayo al respecto lo he llevado a cabo en el artículo "Una reflexión trascendental sobre lo divino", publicado en Endoxa: Series Filosóficas, n 1, 1993, UNED, Madrid, pp. 149-194.

${ }^{96}$ Creación (causación ex nihilo) y libertad (no heterodeterminación) son incompatibles (Kant, Religión III, 2, Observación general, 1, Ak.-Ausg. VI 142, trad. Alianza, p. 142). Difícil sería también medir en qué grado de justicia y de felicidad se encuentra cada uno, y qué niveles de la una correspondería a los de la otra. Es claro y nítido el grito de la humanidad de que el criminal no sea el que triunfe en el mundo, pero ir mucho más allá a una distribución matemática podría dar lugar a la crítica de Hegel, que precede a la de Nietzsche, de que aquí "es la envidia la que se cubre con el manto de la moralidad" ( $F E \mathrm{~W}$ III, 460, trad. F.C.E. p. 365). 
dríamos decir del postulado de la inmortalidad, que cosifica y temporaliza lo que se había pensado como no cosa. Pero las críticas de Hegel van por otro lado.

Según él, en primer lugar, ese postular es tomado poco en serio por la misma conciencia moral. Ésta, en vez de esperar la armonía entre virtud y felicidad más allá del mundo, labora en su misma acción y por su propia particularidad a favor de dicha armonía y de su propio goce, y éste es el primer desplazamiento que la conduce a la hipocresía ${ }^{97}$. Sin embargo en la filosofía práctica de Kant es bien sabido que la relación es exactamente la contraria. La postulación no se realiza por un acto teórico de la conciencia exterior a la acción, sino que es la acción moral misma la que (nolis volis podríamos decir) la lleva a cabo, y sin ella no habría tal postulación. Es allí donde se inscribe esa exigencia de ser llevada a cumplimiento, y eso ocurre así por el mismo querer que la ha engendrado y en la medida en que la engendra. Y no por ello no es tomada en serio esa acción moral, sino que el postulado sólo surge cuando se la toma en serio, pues esto es todo lo más que se le puede exigir moralmente al hombre, a saber, que ponga todo su empeño en la tarea, aunque a la postre el resultado sea insuficiente, y que sólo así espere que lo divino ya en esta realidad provea el resto.

En segundo lugar, objeta Hegel, en el postulado kantiano de Dios no se supera el dualismo entre naturaleza y bien moral; ambos siguen siendo indiferentes entre $s^{98}$, y el proceso asintótico no sólo es contingente, sino que se lanza a un

${ }^{97} \mathrm{FE}$ W III, 454-456, trad. 361-362.

98 "El defecto fundamental de esta moral [kantiana para la Fenomenologia del Espiritu] consiste en ser más conciencia que autoconciencia y de ahí partirá toda la dialéctica siguiente. La conciencia moral no se pone a sí misma, se encuentra a sí misma y encuentra también ante sí un mundo natural [...] indiferente a la moralidad. [...] La conciencia declara por un lado que esos dos mundos son independientes e indiferentes entre sí. Pero por otro lado, la moralidad es lo exclusivamente esencial y libre, la naturaleza debe ser lo inesencial y dependiente. Esta doble afirmación es contradictoria y todos los intentos de resolver esta contradicción [mediante los postulados de la razón práctica] se mostrarán artificiosos e inútiles. [...] La acción [moral misma] une inevitablemente los dos extremos, pero no llega a unirlos perfectamente. [...] El concepto absoluto [hegeliano, que no ha llegado a la plena conciencia de sí en la filosofía de Kant] es el único que permitiría superar la antinomia porque captaría la dualidad, lo otro, a la vez como opuesto y como idéntico. [...] las antinomias kantianas (incluso las de la razón pura) sólo pueden superarse pasando de los modos representativos (dualistas) al modo conceptual (unidad de lo distinto) "(Ramón Valls Plana, Del Yo al Nosotros. Lectura de la Fenomenologia del Espiritu de Hegel, Editorial Estela, Barcelona, 1971, p. 290, 293 y 294).En este último punto sobre "El dualismo entre el deber y el mundo" completo las reflexiones que desarrollé en el parágrafo tercero de mi primer artículo, titulado «El bienestar. La felicidad y el debern, al que ahora también me remito. 
transcurso ilimitado, o sea, hacia la mala infinitud ${ }^{99}$; ella es mala, porque no alcanza aquello hacia lo que tiende, sino que esto queda como algo pensado, sin realidad efectiva. Sólo en el más allá — pero eso es mero pensamiento-, el justo recibiría su merecido y se llegaría a la unificación de virtud y felicidad: "Dios es pues algo postulado; la razón no lo conoce. La armonía no está presente, no es efectivamente real [...] Dios es sólo una creencia, un asentimiento meramente subjetivo, no algo verdadero en y por sín ${ }^{100}$, con fuerza y realidad propia. Lo mismo ocurre con el postulado de la inmortalidad del alma (sin duda uno de los puntos más débiles en el texto kantiano), cuyo objetivo es dar al hombre el tiempo suficiente para que llegue a la aceptación plena del deber, o sea, a la santidad, un tiempo que sin embargo será siempre insuficiente, pues esa unión total de voluntad particular y ley moral en verdad sólo se hallará en Dios. Por consiguiente, "cuando esta contradicción parecía haber sido cubierta, desplazando la realización de la Idea en el tiempo, hacia un futuro donde la Idea también sería, entonces tal condición sensible, como es el tiempo, es más bien lo contrario de una solución a la contradicción, y la correspondiente representación del entendimiento, el progreso sin fin, no es directamente otra cosa que la contradicción misma ya puesta perpetuándose" ${ }^{101}$, haciéndose eterna. Lo absoluto ya no es el fin, sino la tarea interminable. El defecto fundamental de todo dualismo, y en especial el de Kant, es el de separar dos elementos, afirmar que es así como son pensados con verdad y acertadamente, e intentar después unirlos cuando ya resultan irreconciliables ${ }^{102}$. Eso hace que el deber-ser en Kant nunca llegue a cumplirse, a hacerse efectivo ${ }^{103}$. Hegel, por el contrario, piensa que la Idea "no es tan impotente como para sólo deber-ser y no para ser algo efectivamente real» ${ }^{104}$. Más aún, únicamente la Idea es real, la realidad que efectúa su esencia en el fenómeno, y en ello el individuo encuentra su propia esencia y bienestar, pues todo lo verdaderamente real es racional ${ }^{105}$.

¿Pero le va mejor así al individuo en la filosofía hegeliana? Su filosofía de la historia no se caracteriza precisamente por ser compasiva con el infortunio de los suje-

\footnotetext{
${ }^{99}$ Enz. $\$ 94$.

${ }^{100}$ Hegel, HFW XX, 370-371. Véase también Enz $\$ 60$.

${ }^{101}$ Enz. $\$ 60$ (W VIII, 143).

${ }^{102}$ Enz. $\$ 60$ A. Sin embargo, en Kant lo primero es la síntesis, pero una en la que los elementos no son confundidos, pues en la confusión no habría conciencia ni-subjetividad.

${ }^{103} F D \$ 135 \mathrm{~A}$.

${ }^{104}$ Enz $\$ 4$ (W VIII, 49).

${ }^{105}$ Enz $\$ 6$ A.
} 
tos particulares. Y aunque la fuerza de la Idea sea la efectivamente real en el mundo, no por ello nos libramos en Hegel del proceso infinito, pues nunca llegaremos al ideal de la completa realidad efectiva (in der Wirklichkeit) del concepto. Al igual que en Platón, tampoco en Hegel hay adecuación plena entre la Idea y el mundo sensible, aquí en concreto entre ella y su realización histórica. En efecto, pedir "un sistema político puramente racional, sólo racional, ideal", es para Hegel por una parte ciertamente algo correcto, dado que "la razón ha de ser lo dominante", pero también algo incorrecto, pues "la razón, en la realidad efectiva, entra en la exterioridad de la existencia (aplicación, forma de lo positivo), amplia esfera donde sólo el entendimiento tiene su imperio, al que la razón le deja ir a su aire, indiferente sobre si de esta o de aquella manera imperan las circunstancias naturales, etc.» ${ }^{106}$.

Es cierto que la naturaleza en Hegel, al estar constitutivamente habitada por la Idea - la misma que después se hace consciente en el sujeto moral-, pone unas bases más sólidas para un trabajo conjunto de ambas instancias. Eso lo aprendió Hegel de la Filosofía de la Naturaleza de Schelling, y éste lo plasmó brillantemente, por ejemplo, en su obra Sistema del idealismo transcendental de 1800 . Alli se defiende que la natura naturans, la fuerza configuradora de la naturaleza, y con más patencia aún en la naturaleza orgánica (en la que hemos de situar nuestro propio cuerpo), no es ajena a nuestra libertad, sino que es la misma fuerza ideal - real, sólo que situada en un grado menor de potenciación, de manera que ambas -naturaleza y libertad subjetiva - no son sino dos momentos de un mismo proceso autoorganizativo camino de la completa conciencia de sí. Pero tampoco se puede decir que esa naturaleza teleológica esté totalmente ausente en Kant. Sí ocurre eso, ciertamente, en la naturaleza mecánica estudiada en la primera Crítica, dado que se configura desde categorías que excluyen esa subjetividad, pero no si atendemos a la finalidad en la naturaleza estudiada en la tercera de las Críticas, y sobre todo en su segunda parte sobre el Juicio teleológico. Desde allí, la belleza natural puede entenderse como un favor que nos hace la naturaleza para nuestro habitar en el mundo e incitarnos a la cultura ${ }^{107}$. El mismo genio artístico, al no seguir conceptos, se muestra como un «don natural " ${ }^{108}$ capaz de expresar lo que está más allá de todo concepto y de dar la regla al arte. También tenemos la naturaleza orgánica,

${ }^{106} F D \$ 3 \mathrm{Z}$ (W VII, 42-43).

${ }^{107}$ Kant, Crítica del Juicio $\$ 67$, Ak.-Ak. V 380.

${ }^{108}$ O.c., $\$ 46,47$ y 49, Ak.-Ausg. V, 307, 309 y 318. «El genio es un favorecido de la naturaleza" (o. c., $\$ 49$, Ak.-Ausg. V, 318 . 
que parece exhibir una finalidad interna o autoorganización finalista entre el todo y las partes - que incluye evidentemente a nuestro cuerpo, aunque en el texto no se diga expresamente-, claro puente entre nuestra libertad y el mundo objetivo. Pero Kant está más preocupado por los patrones del conocimiento teórico y científico de este modo de naturaleza que por su significado directo en orden a la libertad como acción real, es decir, en cuanto que posibilita que la obligación moral se realice en el mundo. Por eso, dicha finalidad sólo cabría afirmarla para el Juicio reflexionante, según Kant, en la idealidad del "como si» así fuera. Y lo mismo ocurre en relación con la historia, donde parece "como si» la naturaleza nos llevara tortuosamente por el camino del dolor y la prudencia al mismo sitio al que no quisimos ir por el recto camino de la moral: el establecimiento de una cultura y de una Confederación de Estados justos sobre la tierra ${ }^{109}$.

Guardando esas distancias críticas, Kant sostiene en la Primera Parte de su libro La religión dentro de los límites de la mera razón que el mal moral no procede de esa nuestra naturaleza teleológica, pues en ese caso no sería un mal moral, sino físico; este mal moral se origina por un acto de libertad, mientras que las tres disposiciones naturales originarias del hombre, las disposiciones para la animalidad, para la humanidad y para la personalidad, "no son sólo (negativamente) buenas (no están en pugna con la ley moral), sino que son disposiciones para el bien moral (ellas promueven el seguimiento del mismo). Ellas son originales, pues pertenecen a la posibilidad de la naturaleza humana” ${ }^{110}$. Si ahora, acordándonos de lo que se dice en la segunda parte de la Crítica del Juicio, ponemos esto en relación con el principio de finalidad interna, y en esa medida autónoma, que la naturaleza parece exhibir en los seres orgánicos, entre los cuales nosotros hemos de contarnos, y traemos a colación que lo primero en todo acto subjetivo es la síntesis, en donde los elementos no se confunden y por eso pueden ser separados en el análisis, cabría argumentar transcendentalmente a favor de una subjetividad o logos prerreflexivo, que serviría de puente entre libertad y naturaleza ${ }^{111}$.

${ }^{109}$ O. c. $\$ 83$. "Idea de una historia universal desde el punto de vista cosmopolita" y Por la paz perpetua (Suplemento primero), son otros dos textos mayores sobre este asunto. Hay que distinguir aquí diversos tipos de racionalidad: la teórica, la pragmática y la práctica. Todas ellas son afirmación de identidad sintética, de identidad en la diferencia, pero mientras que la razón pragmática es constitutivamente prudente, calculadora, y aceptaría regirse, por ejemplo, por una teoría de juegos, la razón práctica no lo aceptaría en su primer principio.

${ }^{110}$ Religión, Primera Parte, punto 1, Ak.- Ausg. VI. 28.

111 Sobre este asunto me he extendido más ampliamente en el libro Kant: la "Critica del Juicio teleológico" y la corporalidad del sujeto (UNED, Madrid, 1998). 
Lo mismo que ocurre con las citadas disposiciones naturales del hombre sucede con la sensibilidad y las inclinaciones en la moralidad kantiana: ni es lo negativo en sí que haya de ser anulado, ni de ella procede el mal moral ${ }^{112}$. Que el deseo o las inclinaciones sean patológicos, no quiere decir en Kant que sean enfermizos o que la felicidad sea moralmente rechazable, sino que expresan la conciencia y realidad de una limitación heterónoma, de un Leiden o pathos, de una finitud. Para Kant - como hemos visto, y siguiendo en eso a Rousseau-, la disposición originaria natural del hombre es buena — si bien nosotros ingresamos en el ámbito de la moralidad no por ella, sino por nuestro ser libre- ${ }^{113}$. "Pues los impulsos naturales son en sí inocentes y entre ellos y la ley moral no hay propiamente ninguna contienda; convertir en máxima para sí el seguimiento de la ley independiente de esos impulsos, incluso contra ellos, es un acto de libertad [...]. El principio bueno no ha de luchar propiamente contra la sensibilidad (de la carne), pues ella es inocente, sino que la propensión a tomar su máxima, que es libre, según los impulsos de ella, es el principio malo en nosotros" ${ }^{114}$, es decir, no respetar la especificidad ontológica de la libertad, no atender a su contenido de ser, y recoger en la máxima sólo las preocupaciones de la finitud.

\section{Bibliografía}

Una somera bibliografía sobre esta confrontación de Hegel con la moralidad desde el campo de los hegelianos podría ser la siguiente:

Álvarez Gómez, Mariano, "Fundamentación lógica del deber ser en Hegel», en Estudios sobre Kant y Hegel, ed. C. Flórez y M. Álvarez, Universidad de Slamanca, 1982, pp. 171-201.

AMENGUAL, COLL, GaBRiel, La moral como derecho. Estudio sobre la moralidad en la Filosofia del derecho de Hegel, Trotra, Madrid, 2001 (con amplia bibliografía en pp. 431-466).

${ }^{112}$ Religion I, III, Ak.-Ausg. VI, 34-35.

113 Además, si nos atenemos a los usos lingüísticos kantianos, encontraríamos otro sentido del término "deseo", que suele ser totalmente olvidado: la voluntad racional y moral es denominada por Kant das obere Begehrungsvermögen, o sea, la facultad superior de desear. Ese "deseo" superior sí que expresaría nuestra libertad, nuestro ser más originario, bien cercano al amor intellectualis Dei spinozista.

${ }^{114}$ LB Fortschritte, Ak.- Ausg. XX, 346-347. 
AMERIKS, KaRL, "Probleme der Moralität bei Kant und Hegel", en Das Recht der Vernunft. Kant und Hegel über Denken, Erkennen und Handeln, Hrsg. Ch. Fricke et alt., Frommann, Stuttgart, 1995, pp. 263-289.

BITSCH, BRIGITTE, Sollenbegriff und Moralitätskritik bei G. W.F. Hegel. Interpretationen zur "Wissenschaft der Logik", "Phänomenologie" und "Rechtsphilosophie", Grundmann, Bonn, 1977.

Cesa, Claudio, "Tra Moralität e Sittlichkeit. Sul confronto di Hegel con la filosofia pratica di Kant", en Hegel interprete di Kant, Prismi, Napoli, 1981, pp. 147-178. "Hegel und die Kantische Moralität", en Das Recht der Vernunft. Kant und Hegel über Denken, Erkennen und Handeln, Hrsg. Ch. Fricke et alt., Frommann, Stuttgart, 1995, pp. 291-309.

COLLINS, ARDIS B., "Hegel's Critical Appropriation of Kantian Morality", en Beyond Liberalism and Communitarianism. Studies in Hegel's Philosophy of Right, ed. Robert R. Williams, State University of New York Press, 2001, pp. 21-39.

Horstmann, Rolf-PeTER, «Kant und der 'Standpunkt der Sittlichkeit'. Zur Destruktion der Kantischer Philosophie durch Hegel", en Hegel critique de Kant, Revue Internationale de Philosophie, volume 53, n.o 210, 4/1999, pp. 567-582.

JERMANN, Chr., Anspruch und Leistung von Hegels Rechtsphilosophie, Stuttgart, 1987 (pp. 101-144).

KNOWLES, Dudley, Routledge philosophy guidebook to Hegel and the "Philosophy of Rigth", Routledge, London and New York, 2002.

Menegoni, Francesca, Moralitá e morale In Hegel, Liviana, Padova, 1982.

Soggetto e struttura dell'agire in Hegel, Verifiche, Trento, 1993.

Nusser, K. H., «Die Moralität in Hegels Rechtsphilosophie», en Die Rechtsphilosophie des deutschen Idealismus, Hrsg. V. Hösle, Meiner, Hamburg, 1989.

PePerzak, AdrianN TheOdOOR, "Los fundamentos de la ética según Hegel», en G. Amengual (ed.), Estudios sobre la filosofia del derecho de Hegel, Centro de Estudios Constitucionales, Madrid, 1989, pp. 93-120.

Hegel praktische Philosophie, Frommann, Stuttgart, 1991 (pp. 186-236).

Modern Freedom. Hegel's legal, moral, and political Philosophy, Kluwer Academic

Publishers, Dordrecht, 2001.

Quante, Michael, Hegels Begriff der Handlung, Frommann, Stuttgart, 1993.

Reboul, Olivier, "La dignité humaine chez Kant", en Revue de Metaphysique et de Morale 80 (1975), pp. $85-100$. 
RITTER, JOACHIM, "Moralidad y eticidad. Sobre la confrontación de Hegel con la ética kantiana", en Estudios sobre la 'Filosofia del Derecho' de Hegel, ed. Gabriel Amengual, Centro de Estudios Constitucionales, Madrid, 1989, pp. 143-169.

SCHNÄDELBACH, HERBERT, Hegels praktische Philosophie. Ein Kommentar der Texte in der Reihenfolge ihrer Entstehung, Suhrkamp, Frankfurt, 2000.

SIEP, LUDWIG, “¿Qué significa 'superación de la moralidad en eticidad' en la 'Filosofía del Derecho' de Hegel?», en Estudios sobre la 'Filosofia del Derecho' de Hegel, ed. Gabriel Amengual, Centro de Estudios Constitucionales, Madrid, 1989, pp.171-193.

Praktische Philosophie im Deutschen Idealimus, Suhrkamp, Frankfurt, 1992.

StANGUENNEC, ANDRE, Hegel critique de Kant, P.U.F., Paris, 1985.

VAlCARCEL, AMElia, Hegel y la ética. Sobre la superación de la mera moral, Anthropos, Barcelona, 1988.

Varios, Hegel interprete di Kant, ed. Valerio Verra, Prismi, Napoli, 1981. Hegel-Jahrbuch 1987.

WALSCH, W. H., Hegelian Ethics, London, 1969 (sobre todo pp. 21-34; La ética hegeliana, Valencia, 1976 (pp. 39-58).

WoOD, Allen, Hegel's ethical thought, Cambridge University Press, 1990 (reed. 2002). "Hegel's Critique of Morality", en G. W. F. Hegel: Grundlinien der Philosophie des Rechts, Hrsg. Ludwig Siep, Akademie Verlag, Berlin, 1997. 